\title{
Local Health Departments' Activities to Address Health Disparities and Inequities: Are We Moving in the Right Direction?
}

\author{
Gulzar H. Shah * and John P. Sheahan \\ Received: 15 August 2015; Accepted: 13 November 2015; Published: 23 December 2015 \\ Academic Editors: Mark Edberg, Barbara E. Hayes, Valerie Montgomery Rice and Paul B. Tchounwou \\ Jiann-Ping Hsu College of Public Health, Georgia Southern University, Statesboro, GA 30460, USA; \\ js02904@georgiasouthern.edu \\ * Correspondence: gshah@georgiasouthern.edu; Tel.: +1-912-478-2419; Fax: +1-912-478-5811
}

\begin{abstract}
Context: Health disparities are among the critical public health challenges. Objectives: To analyze the extent to which local health departments (LHDs) perform activities for addressing health disparities, changes in proportion of LHDs' performing those activities since 2005, and factors associated with variation in such engagement. Methods: We used the 2013 National Profile of LHDs Survey to perform Logistic Regression of activities LHDs performed to address health disparities. Results: About 20 percent of LHDs did not perform any activity to address health disparities. Significant decreases occurred since 2005 in the proportion of LHDs that performed health disparity reduction/elimination activities for four activities. LHD characteristics significantly associated $(p \leqslant 0.05)$ with the increased likelihood of performing activities to address health disparities were: recent completion of community health assessment, community health improvement plan and agency wide strategic plan. Other significant positive impacts on such activities included per capita expenditures, local governance, having one or more local boards of health, larger population size and metropolitan status of the LHD jurisdiction. Conclusions: Reduced infrastructural capacity of LHDs has resulted in fewer LHDs addressing health disparities in their jurisdictions. LHD characteristics associated with higher performance of activities for health disparity reduction identified by this research have important policy implications.
\end{abstract}

Keywords: health disparities; community health assessment; community health improvement plan; strategic planning; local health departments; health inequities

\section{Introduction}

According to Braveman, health disparities are differences in the quality of healthcare and health status among population subgroups based on race, ethnicity, sexual orientation, immigration status, age, and socioeconomic status [1], and they represent a persistent public health problem [1-8]. Health disparities can lead to differing outcomes and quality of life among individuals with different demographic backgrounds [2-12]. Health disparities exist in the United States, in various forms and across various subgroups, including race/ethnicity categories, age, gender, sexual orientations and other social segments in regards to inequalities in screening, rates of diseases contracted, inequities in mortality, and a lack of legislative and judicial power [13-23]. Various national initiatives have tried to garner awareness about the existence of racial and social disparities in the United States. National plans, such as Healthy People 2020, are a call to action for reducing health disparities by addressing social determinants of health among disadvantaged populations.

In order to address the persistent problems of disparities in health, local health departments (LHDs) are expected to proactively identify such disparities in their communities by conducting 
community health assessments (CHA), preparing an agency-wide strategic plan (CHIP) that is reflective of CHA, and address these disparities by developing a strategic plan (SP) [24-28]. LHDs who undergo these activities are potentially more able to understand and address health disparities in their jurisdictions, because they have data and evidence about the existence of the disparities and the population groups affected by them [26,27]. With an increasing emphasis on identifying upstream root-causes of public health issues by focusing on social determinants of health, it is critical to look at these issues from a broad public health perspective concerning social determinants of health due to the far reaching health disparities between various demographic and social groups in the United States [11,12,29]. Multiple factors influence health disparities such as access to care, socio-economic factors, the physical environment, and education [2].

LHDs are at the vanguard in the fight to eliminate disparities in the population [30], and they are strategically positioned to address this issue as they represent the frontline of public health. Using the National Association of County and City Health Officials (NACCHO) Profile Study data, we can estimate their ability and activities to address health disparities in their communities. Additionally, because they have intimate knowledge of their communities they are in a better position than other types of health agencies to eliminate disparities specific to their jurisdictions [30-34].

While various national initiatives (e.g., accreditation of public health agencies through Public Health Accreditation Board or PHAB) underscore the need to address health disparities, it is important to gauge the level of effort and strategy at the local level, given that reduced staff and budgets may have affected LHDs' infrastructure and abilities to address health disparities [32-36]. LHDs can make some difference by working with strategic partners in reducing the inequities leading to disparities or assuring access to health care or by directly providing primary care on a limited scale, particularly to underserved and disenfranchised population subgroups [35,37].

There appears to be significant gaps in the literature concerning how local health departments address health disparities. The objective of this study is to examine and fill in knowledge gaps concerning LHDs, specifically by analyzing (1) the extent to which LHDs engage in strategies and activities for addressing health disparities and (2) variation in involvement of LHDs in specific activities in their efforts to address health disparities in their communities. Such sub-group comparisons are significant because important differences exist in health issues and needs across LHDs.

\section{Methods}

\subsection{Study Design and Sample}

We used three waves of the National Profile of LHDs (Profile) Study for which survey data were collected by National Association of County and City Health Officials (NACCHO), using census approach and web-based structured questionnaires, administered to all LHDs meeting NACCHO's definition of a local health department. Each of these surveys used a cross-sectional design, census approach and a comprehensive set of questions to elucidate numerous aspects of LHDs' infrastructural capacities and services, with response rates of $80 \%, 83 \%$, and $79 \%$ respectively in 2005,2008 , and 2013 [38-41]. While the questions on LHDs' engagement in activities to reduce disparities were administered to all LHDs in the 2008 Profile survey, these questions were administered to only sub-samples of 519 LHDs in the 2005 Profile survey and 625 LHDs in 2013 with response rates of 81 percent in both studies $[38,41]$. These samples were selected using stratified random sampling without replacement using seven strata defined by the size of the population in the LHD jurisdiction. The multivariable analyses were conducted using the 2013 survey because pooling of the data from multiple years was not possible due to variation in sampling designs across survey years.

\subsection{Measures}

Our primary measure of interest was the extent to which LHDs in the United States engage in activities to address health disparities in the past two years. In 2005, LHDs were provided the 
following definition of inequities, "Health inequity is a phrase used to describe a difference in the health of groups in the population that is both avoidable and unfair. In the United States, health inequities exist for almost all conventionally measured health outcomes. The causes of health inequities include racism and poverty as well as differences in the quality of living environments, including homes, food, air, water, jobs, education, and transportation". LHDs were then asked to "Check each activity that your LPHA has done in the past three years": (1) "Describing health disparities in your jurisdiction using data"; (2) Conducting original research that links health disparities to differences in social or environmental conditions; (3) Educating elected or appointed officials about health disparities and their causes; (4) Training your workforce on health disparities and their causes; (5) Recruiting workforce from communities adversely impacted by health disparities; (6) Prioritizing resources and programs specifically for the reduction in health disparities; (7) Taking public policy positions on health disparities (through testimony, written statements, media, etc.); and (8) Supporting community efforts to change the causes of health disparities.

In the 2008 Profile Survey, disparities were defined as, "Health disparities can be defined as differences in health status that occur among population groups", and LHDs were asked to "Check each activity that your LHD has done in the past two years to address health disparities" with the same activity list of eight activities used in 2005. In the 2013 Profile Survey, the definition of health disparities and the questions remained the same but an additional activity was included in the list. In addition to the ones included in the 2005 and 2008 surveys; offering staff training in cultural/linguistic competency was included in the 2013 Profile Survey. Each of these activities resulted in dichotomous variables, coded as checked (or yes), or un-checked (or no). For the multivariable analyses (Logistic Regression Models), we selected 6 activities for the analyses, excluding the three least commonly performed activities. The least performed activities were not included in the multivariable analyses because they presented the risk of small and zero cells in those analyses, as they would have increased the risk of chance variation.

The independent variables included those characteristics of LHDs and LHD leadership theoretically or empirically linked with LHD's knowledge about existence of disparities in their jurisdiction [24], or infrastructural capacities $[9,24,30,31]$, enabling them to perform activities to address disparities. Population of LHD jurisdiction (in 10,000) and per capita expenditures (coded as, not reported; quintiles, 1st < \$19; 2nd \$19-\$29; 3rd \$30-\$46; 4th \$46-\$75; 5th $\geqslant 76$ ), reflected infrastructural capacity and economies of scale known to effect similar performance of public health functions by LHD [41]. Completion of community health assessment (CHA), community health improvement plan (CHIP) and completion of strategic plan (SP) were coded as "completed within 5 years", and "No/Not within 5 years AND no plan in the next year", to match PHAB requirement of completion of these pre-requisites within 5 years to be considered current [42]. The CHA, CHIP and SP are theoretically relevant in that they are instrumental in identification of health disparities and formal prioritization. Number of information systems implemented by LHDs, was operationalized using the question, "Indicate your LHD's level of activity for each of the following health informatics areas". The question included the following informatics areas, and the variable was formulated by counting the number implemented, (1) Electronic Health Records (EHRs); (2) Health Information Exchange (HIE); (3) Immunization Registry (IR); (4) Electronic Disease Reporting System (EDRS); (5) Electronic Lab Reporting (ELR); and (6) Electronic syndromic surveillance system. Information systems can be instrumental in assistance with identification of disparities (e.g., immunization systems can help identify disparities in completion of immunization). LHDs' governance was reflected by two variables, having one or more local boards of health vs. no local boards of health, and a governance category that reflects the centralization of LHD governance relative to the state health department. Presence of local boards of health (LBOH) also reflected LHDs' connectivity and their governing body's exposure to diverse perspectives. The metropolitan vs. non-metropolitan status of the LHD jurisdiction was created based on the NCHS definition for urban-rural counties. For LHDs not consisting of single county or those consisting of other complex structures, NACCHO's GIS data table [43] was used to designate 
metropolitan (when all of the geographic units were metropolitan), non-metropolitan (when all of the geographic units were non-metropolitan), predominantly metropolitan (when metropolitan areas of the LHD had greater population than non-metropolitan), and predominantly non-metropolitan (when non-metropolitan areas of the LHD had greater population than metropolitan).

\subsection{Analysis}

We performed all analyses for this study using SPSS Statistics version 23 (IBM Corporation, Armonk, NY, USA). In order to compute estimates that are generalizable to all LHDs, we accounted for sampling design and disproportionate response rate by population category, by using statistical weights computed for Module 3 for 2005 data, Core set of questions for 2008, and Module 2 for 2013. To highlight the distribution of LHD characteristics we computed descriptive statistics for the categorical variables and means and standard deviation for the continuous variables. For the multivariable analysis, we computed six separate logistic regression models, with each activity as the dichotomous dependent variable.

\section{Results}

Table 1 shows the descriptive characteristics of the LHDs in the study. As indicated in Table 2, there was a significant decrease in the number of LHDs' activities intended to reduce health disparities from 2005-2013. In this time period, the percentage of LHDs engaging in educating elected or appointed officials about health disparities and their causes decreased significantly from $55.5 \%$ in 2005 to $44 \%$ in 2013. The proportion of LHDs recruiting workforce, from communities adversely impacted by health disparities decreased from $24.8 \%$ (2005) to $17.8 \%$ (2013). LHDs engaged in prioritizing resources and programs specifically for the reduction in health disparities decreased from $50.2 \%$ (2005) to $33.6 \%$ (2013). Lastly, the percentage of LHDs taking public policy positions on health disparities decreased from $26.7 \%$ (2005) to $15.8 \%$ (2013).

Table 1. Percent distribution of the LHDs in the sample by infrastructural, governance and other characteristics, 2013 National Profile of LHDs Survey.

\begin{tabular}{lcc}
\hline & N (un-Weighted) & Percent (Weighted) \\
\hline Per Capita Expenditures (Quintiles rounded to whole dollar) & & \\
$<\$ 19$ & 87 & 16.7 \\
$\$ 19-\$ 30$ & 75 & 13.8 \\
$\$ 31-\$ 45$ & 74 & 14.5 \\
$\$ 46-\$ 75$ & 76 & 14.7 \\
$\$ 76$ or more & 61 & 28.2 \\
Not Reported & 132 & 71.6 \\
\hline CHA completed within 5 years & 363 & 12.0 \\
Yes, within 5 years & 55 & 16.4 \\
No but plan to in the next year & 78 & \\
No/Not within 5 years AND no plan in the next year & & 54.3 \\
\hline CHIP completed within 5 years & 278 & 23.1 \\
Yes, within 5 years & 114 & 22.7 \\
No but plan to in the next year & 104 & \\
No/Not within 5 years AND no plan in the next year & & 47.3 \\
SP completed within 5 years & 239 & 22.7 \\
Yes, within 5 years & 116 & 30.0 \\
No but plan to in the next year & 138 & \\
No/Not within 5 years AND no plan in the next year & & \\
\hline
\end{tabular}


Table 1. Cont.

\begin{tabular}{lcc}
\hline & N (un-Weighted) & Percent (Weighted) \\
\hline Type of governance & & \\
Decetralized (local governance) & 405 & 79.5 \\
$\quad$ Centralized (i.e., state governance)/shared & 100 & 20.5 \\
\hline LHD has 1 or mroe LBOH & 150 & 28.9 \\
$\quad$ No & 345 & 71.1 \\
$\quad$ Yes & & 36.1 \\
\hline Metropolitan status of the LHD jurisdiction & 236 & 63.9 \\
$\quad$ Metropolitan & Number & Mean (variance) \\
$\quad$ Non-metropolitan) & 505 & 1.247 (13.695) \\
\hline & 493 & $3.044(2.036)$ \\
Population (in 100,000 s) & & \\
Number of information systems (ELR, HIE, IR, EDRS, ELR, & & \\
\hline
\end{tabular}

Table 2. Percent of LHDs conducting specific activities to address health disparities, 2005, 2008, and 2013.

\begin{tabular}{|c|c|c|c|c|c|c|c|c|c|}
\hline \multirow{3}{*}{$\begin{array}{l}\text { Activities to Address Health } \\
\text { Disparities }\end{array}$} & \multicolumn{3}{|c|}{$\begin{array}{l}2005 \text { (Activities in } \\
\text { Past } 3 \text { Years) }\end{array}$} & \multicolumn{3}{|c|}{$\begin{array}{l}2008 \text { (Activities in } \\
\text { Past } 2 \text { Years) }\end{array}$} & \multicolumn{3}{|c|}{$\begin{array}{l}2013 \text { (Activities in } \\
\text { Past } 2 \text { Years) }\end{array}$} \\
\hline & \multirow{2}{*}{$\%$} & \multicolumn{2}{|c|}{$\begin{array}{c}\text { Confidence } \\
\text { Interval }\end{array}$} & \multirow{2}{*}{$\%$} & \multicolumn{2}{|c|}{$\begin{array}{l}\text { Confidence } \\
\text { Interval }\end{array}$} & \multirow{2}{*}{$\%$} & \multicolumn{2}{|c|}{$\begin{array}{c}\text { Confidence } \\
\text { Interval }\end{array}$} \\
\hline & & LL & UL & & LL & UL & & $\overline{\text { LL }}$ & UL \\
\hline $\begin{array}{l}\text { Describing health disparities in your } \\
\text { jurisdiction using data }\end{array}$ & 54.9 & 49.5 & 60.4 & 51.5 & 49.4 & 53.6 & 57.2 & 52.4 & 61.9 \\
\hline $\begin{array}{l}\text { Conducting original research that links } \\
\text { health disparities to differences in social } \\
\text { or environmental conditions }\end{array}$ & 11.5 & 8.2 & 14.8 & 11.2 & 9.9 & 12.4 & 10.9 & 8.2 & 13.7 \\
\hline $\begin{array}{l}\text { Educating elected or appointed officials } \\
\text { about health disparities and their causes }\end{array}$ & 55.5 & 50.1 & 61.0 & 45.6 & 43.6 & 47.7 & 44.0 & 39.3 & 48.6 \\
\hline $\begin{array}{l}\text { Training your workforce on health } \\
\text { disparities and their causes }\end{array}$ & 51.4 & 46.0 & 56.8 & 49.7 & 47.7 & 51.8 & 48.1 & 43.4 & 52.8 \\
\hline $\begin{array}{l}\text { Recruiting workforce from communities } \\
\text { adversely impacted by health disparities }\end{array}$ & 25.8 & 21.3 & 30.2 & 20.1 & 18.5 & 21.8 & 17.8 & 14.5 & 21.2 \\
\hline $\begin{array}{l}\text { Prioritizing resources and programs } \\
\text { specifically for the reduction in health } \\
\text { disparities }\end{array}$ & 50.2 & 44.8 & 55.6 & 39.7 & 37.7 & 41.7 & 33.6 & 29.2 & 37.9 \\
\hline $\begin{array}{l}\text { Taking public policy positions on health } \\
\text { disparities (through testimony, written } \\
\text { statements, media, etc.) }\end{array}$ & 27.7 & 23.1 & 32.4 & 20.2 & 18.6 & 21.8 & 15.8 & 12.5 & 19.0 \\
\hline $\begin{array}{l}\text { Supporting community efforts to change } \\
\text { the causes of health disparities }\end{array}$ & 62.3 & 56.9 & 67.7 & 58.4 & 56.4 & 60.5 & 54.4 & 49.7 & 59.1 \\
\hline None of the above activities & 20.9 & 16.2 & 25.7 & 22.0 & 20.3 & 23.8 & 16.0 & 12.3 & 19.6 \\
\hline $\begin{array}{l}\text { Offering staff training in } \\
\text { cultural/linguistic competency }\end{array}$ & $x$ & $x$ & $x$ & $x$ & $x$ & $X$ & 47.3 & 42.6 & 52.0 \\
\hline
\end{tabular}

Notes: the confidence bounds in bold indicate a statistically significant change from 2005 to 2013 at $p \leqslant 0.05$;

$X$ in the last row indicates that data were not collected on this item in the particular year. Abbreviations: LL, lower limit of the confidence interval; UL, Upper limit of the confidence interval.

Results of our multivariable logistic regression models (Table 3) show that per capita expenditure had, for the most part, a significant positive association with all of the dependent variables except offering staff training in cultural/linguistic competency. For most of the activities, LHDs with higher per capita expenditures had higher odds of performing the activities to reduce health disparities. Having completed a CHA within five years (vs. no and no plans for next 12 months) was positively and significantly associated with activities that addressed health disparities in all of the categories except training LHDs' workforce. 
Table 3. Logistic regression of activity performed by LHDs in the past two years to address health disparities, defined as differences in health status that occur among population groups

\begin{tabular}{|c|c|c|c|c|c|c|c|c|c|c|c|c|}
\hline \multirow[t]{2}{*}{ LHD Characteristics } & \multicolumn{2}{|c|}{$\begin{array}{l}\text { Describing Health } \\
\text { Disparities in Your } \\
\text { Jurisdiction Using Data }\end{array}$} & \multicolumn{2}{|c|}{$\begin{array}{l}\text { Supporting } \\
\text { Community Efforts to } \\
\text { Change the Causes of } \\
\text { Health Disparities }\end{array}$} & \multicolumn{2}{|c|}{$\begin{array}{c}\text { Training Your Workforce } \\
\text { on Health Disparities and } \\
\text { Their Causes }\end{array}$} & \multicolumn{2}{|c|}{$\begin{array}{l}\text { Offering Staff Training in } \\
\text { Cultural/Linguistic } \\
\text { Competency }\end{array}$} & \multicolumn{2}{|c|}{$\begin{array}{l}\text { Educating Elected or } \\
\text { Appointed Officials about } \\
\text { Health Disparities and } \\
\text { Their Causes }\end{array}$} & \multicolumn{2}{|c|}{$\begin{array}{l}\text { Prioritizing Resources and } \\
\text { Programs Specifically for } \\
\text { the Reduction in } \\
\text { Health Disparities }\end{array}$} \\
\hline & AOR & $p$ & AOR & $p$ & AOR & $p$ & AOR & $p$ & AOR & $p$ & AOR & $p$ \\
\hline Per Capita Expenditures $(v s .<\$ 19)$ & & 0.000 & & 0.000 & & 0.000 & & 0.539 & & 0.000 & & 0.000 \\
\hline$\$ 19-\$ 30$ & 4.379 & 0.000 & 1.329 & 0.084 & 0.957 & 0.777 & 0.958 & 0.790 & 2.902 & 0.000 & 1.809 & 0.000 \\
\hline$\$ 31-\$ 45$ & 1.096 & 0.593 & 0.699 & 0.029 & 0.779 & 0.112 & 1.034 & 0.835 & 0.692 & 0.025 & 0.852 & 0.342 \\
\hline$\$ 46-\$ 75$ & 1.925 & 0.000 & 0.695 & 0.037 & 0.539 & 0.000 & 1.163 & 0.371 & 1.351 & 0.076 & 1.156 & 0.406 \\
\hline$\$ 76$ or more & 1.419 & 0.033 & 0.938 & 0.683 & 0.962 & 0.797 & 0.942 & 0.696 & 1.429 & 0.019 & 0.755 & 0.089 \\
\hline $\begin{array}{l}\text { CHA completed within } 5 \text { years }(v s \text {. No/Not within } \\
5 \text { years AND no plan in the next year) }\end{array}$ & & 0.000 & & 0.000 & & 0.467 & & 0.000 & & 0.000 & & 0.014 \\
\hline No but plan to in the next year & 1.348 & 0.196 & 0.883 & 0.584 & 1.145 & 0.534 & 0.840 & 0.450 & 0.463 & 0.001 & 0.485 & 0.004 \\
\hline $\begin{array}{l}\text { CHIP completed within } 5 \text { years (vs. No/Not } \\
\text { within } 5 \text { years AND no plan in the next year) }\end{array}$ & & 0.032 & & 0.006 & & 0.000 & & 0.046 & & 0.000 & & 0.000 \\
\hline Yes, within 5 years & 1.558 & 0.009 & 1.540 & 0.010 & 1.997 & 0.000 & 1.238 & 0.198 & 1.425 & 0.040 & 2.722 & 0.000 \\
\hline No but plan to in the next year & 1.405 & 0.068 & 1.798 & 0.001 & 2.070 & 0.000 & 1.556 & 0.017 & 2.318 & 0.000 & 2.935 & 0.000 \\
\hline $\begin{array}{l}\text { SP completed within } 5 \text { years ( } v s \text {. No/Not within } 5 \\
\text { years AND no plan in the next year) }\end{array}$ & & 0.000 & & 0.000 & & 0.000 & & 0.001 & & 0.000 & & 0.000 \\
\hline Yes, within 5 years & 3.378 & 0.000 & 2.216 & 0.000 & 2.219 & 0.000 & 1.454 & 0.001 & 1.649 & 0.000 & 1.579 & 0.000 \\
\hline No but plan to in the next year & 2.225 & 0.000 & 2.503 & 0.000 & 1.480 & 0.003 & 1.012 & 0.932 & 2.413 & 0.000 & 1.823 & 0.000 \\
\hline Local governance ( $v s$. state/shared governance) & 1.618 & 0.001 & 1.233 & 0.120 & 1.530 & 0.001 & 1.861 & 0.000 & 0.871 & 0.294 & 0.946 & 0.700 \\
\hline LHD has 1 or more LBOH ( $v s$. None) & 1.283 & 0.041 & 1.389 & 0.004 & 1.254 & 0.038 & 1.125 & 0.288 & 1.330 & 0.010 & 1.308 & 0.023 \\
\hline Population (in $100,000 \mathrm{~s}$ ) & 1.242 & 0.000 & 1.607 & 0.000 & 1.116 & 0.000 & 1.096 & 0.000 & 1.040 & 0.030 & 1.105 & 0.000 \\
\hline $\begin{array}{l}\text { Number of information systems (ELR, HIE, IR, } \\
\text { EDRS, ELR, ESS) implemented by LHD }\end{array}$ & 1.208 & 0.000 & 1.071 & 0.044 & 1.033 & 0.314 & 1.364 & 0.000 & 1.221 & 0.000 & 1.273 & 0.000 \\
\hline
\end{tabular}

Abbreviations: AIRR, Adjusted Incident Rate Ratio; EHR, Electronic Health Records; HIE, Health Information Exchange; IR, Immunization Registry, EDRS, Electronic Disease

Reporting System; ELR, Electronic Lab Reporting; ESS, Electronic disease surveillance; CHA, community health assessment; CHIP, community health improvement plan; SP, Strategic Plan; CI, confidence interval; LHD, local health department; LBOH, Local Board of Health; Bold values indicate that the subgroup differences are significant at $p \leqslant 0.05$. 
Having completed a CHIP within five years (vs. no and no plans for next 12 months) significantly increased the odds of performing all six activities to address health disparities, including describing health disparities using data (AOR, 1.56), supporting community efforts to change the causes of health disparities (AOR, 1.54), training your workforce on health disparities and their causes (AOR, 2.00), offering staff training in cultural/linguistic competency (AOR, 1.24), educating elected or appointed officials about health disparities and their causes (AOR, 1.43), and prioritizing resources and programs specifically for the reduction in health disparities (AOR, 2.72). Having completed a strategic plan within 5 years (vs. no and having no plans for next 12 months) was also significantly associated with increased odds of performing all six activities-describing health disparities (AOR, 3.38), supporting community efforts (AOR, 2.10), training your workforce (AOR, 2.10), offering staff training (AOR, $1.45)$, educating elected or appointed officials (AOR, 1.65), and prioritizing resources and programs (AOR, 1.58).

Odds for health disparity prevention activities for LHDs with decentralized (i.e., local) governance ( $v s$. centralized/state or shared governance) were significantly higher in three of the six categories-describing health disparities (AOR, 1.62), training your workforce (AOR, 1.53), and offering staff training (AOR, 1.86). The size of population in LHD jurisdiction was also positively associated with all six of the dependent variables, including describing health disparities (AOR, 1.24), supporting community efforts (AOR, 1.61), training your workforce (AOR, 1.12), offering staff training $(A O R, 1.10)$, educating elected or appointed officials (AOR, 1.04), and prioritizing resources and programs (AOR 1.11). LHD with one or more LBOH (vs. none) had significant higher odds of performing all activities (except offering staff training in cultural/linguistic competency), including describing health disparities (AOR, 1.28), supporting community efforts (AOR, 1.39), training LHD workforce (AOR, 1.25), educating elected or appointed officials (AOR, 1.33), and prioritizing resources and programs (AOR, 1.31). Superior informatics capacity of LHDs improved their odds of performing activities to address health disparities, including describing health disparities (AOR, 1.21), supporting community efforts (AOR, 1.07), offering staff training (AOR, 1.36), educating elected or appointed officials (AOR, 1.22), and prioritizing resources and programs (AOR, 1.27). Lastly, the metropolitan status of a LHD (vs. non-metropolitan) was significantly associated with increased odds of three activities-describing health disparities (AOR, 1.71), educating elected or appointed officials (AOR, $1.55)$, and prioritizing resources and programs (AOR, 1.25).

\section{Discussion}

Some of LHDs' activities to address disparities declined in the year 2008 and further declined in 2013, compared with 2005. This is noteworthy, given that an increase was expected in the proportion of LHDs engaging in such activities, in the post Affordable Care Act landscape characterized by efforts to improve population health through prevention and improved access to care among traditionally underserved population. It is also of note considering numerous national bodies (e.g., PHAB) recommending that public health agencies ought to tackle health disparities by reducing inequities in social determinants of health. Of particular note is our finding that shows a reduction in frequency of LHDs performing activities concerning public policy, such as taking public policy positions on health disparities (through testimony, written statements, media, etc.), or educating elected or appointed officials about health disparities and their causes.

Health disparities result primarily from socio-political and economic inequities (social determinants of health) among population subgroups based on race/ethnicity, gender, age, immigration status, sexual orientation, and other individual or subgroup characteristics [44,45]. Having fewer LHDs informing activities to educate elected or appointed officials about health disparities and their causes has the potential to influence policies concerning a multitude of socio-political and economic factors that can impact health disparities. Reduction in the proportion of LHDs engaged in recruiting workforce from communities adversely impacted by health disparities is perhaps more clearly indicative of impact of 2007-2008 recession on LHDs' activities [46]. Overall the decline in 
workforce and repeated budget cuts year after year [34] may have reduced LHDs' ability to recruit more staff in general, which in turn might have resulted in a reduction in this activity. Decline in post-recession budgets is perhaps also the reason for LHDs' inability to prioritize resources and programs specifically targeting reduction in health disparities [46].

Our results from multivariable analyses also have important implications for public health practice and policy. Positive association between completing $a \mathrm{CHA}$, - with all but one dependent variable is indicative of the value of data-driven public health practice. In order to consider strategies for addressing health disparities, LHDs must know the specific health indicators for which disparities exit and CHA can be instrumental in identifying those specific health disparity indicators [23]. Completion of CHIP is also positively associated with an LHD's ability to administer programs addressing health disparities. PHAB standards require LHDs to sequence CHA and CHIP so that their CHA must inform their CHIP, which means that priority health issues highlighted in CHA get incorporated into CHIP [27]. This explains the association of CHIP and health disparities. An agency-wide strategic plan (SP) helps an agency outline their future strategic goals and initiatives. Without a proper well thought out SP an agency may not be able to fully utilize all of its resources. Therefore, LHDs with a SP that is properly informed by CHA and CHIP are likely to designate addressing health disparities a high strategic priority if health disparities are highlighted in their CHA and CHIP [47].

Decentralized governance (as opposed to state or shared governance)—was associated with a LHDs' ability to describe disparities, training their workforce, and offering staff assistance. Centralized governance of the LHD-may make it easier for the state (as umbrella) agency to facilitate these activities for LHDs, lessening LHDs' need to directly engage in these activities. The population size in a LHD's jurisdiction is among the strongest factors influencing LHDs' engagement in activities to address health disparities, perhaps due to economies of scale and scope. A larger size population in a LHD jurisdiction was significantly associated with greater likelihood of performing all six activities to address health disparities. LHDs with higher population may have more resources and lower unit cost to assess the existence of health disparities in their jurisdiction and if needed, formulate strategies to address health disparities [48].

The health informatics capacity of LHDs- was also positively associated with LHDs' engagement in activities to curb health disparities. The number of information systems a LHD possesses is significant in four out of the 6 dependent variable categories. Health informatics capacity can increase LHDs' ability to collect and communicate disparities-related data, improving their prospects for conducting activities to address health disparities.

Currently, most of the activities LHDs perform to combat health disparities focus on disparities and some of their proximate determinants (e.g., showing the overall overlay between poverty and health outcomes), but a shift in focus is needed in identifying upstream factors and inequities responsible for creating and sustaining economic and health disparities. For instance why is the life expectancy 10 years apart in neighborhoods that are two miles apart?

To tackle health disparities adequately, instead of focusing on health disparities as outcomes for the population, LHDs' may want to consider partnering with other institutions and critically evaluate institutional practices that create inequities. LHDs' strategies and activities that examine decisions of social institutions and how the integration of these decisions into institutional practices create inequities and social injustices can be effective in preventing health disparities. Highlighting these inequities and working with other stakeholders to bring about policy and practice changes in the respective institutions can be very fruitful.

This might mean simple things, such as completion of CHA by LHDs not only looking at the health outcomes and racial/ethnic disparities with respect to those outcomes but also looking at the data that will identify the root causes of disparities. We see from the results that completing a CHA and a CHIP were significantly associated with a LHDs performing activities to reduce health disparities. Thus, we can see that encouraging LHDs to engage in these activities could increase their efforts to address inequities in their jurisdictions. Enabling better federal and state policy to encourage the use 
of CHA, CHIP, and SP in LHDs could increase LHDs effort to reduce disparities in their communities, some of which the NACCHO profile study has shown to be decreasing since 2005. When patterns of inequalities are indicated by the CHA data, LHDs, in preparing the community health improvement plan (CHIP), should not simply assume that these differences are merely bad luck, or unfortunate events, or caused by people's individual behavior. They must try to explain the patterns as resulting from historic and/or ongoing policies and institutional practices that created these inequities over time, not necessarily intentionally, but because people's needs were ignored for the sake of other competing interests.

\section{Limitations}

Our study has several limitations, hence our findings should be interpreted within this context. First, the Profile study, the source of secondary data for our analysis, comprises a broad range of topics on public health practice and infrastructural capacities. This study is not, however, designed to provide exhaustive data on all of the topics. The future research may use qualitative or mixed methods approach to ask more critical and detailed questions. Secondly, the questions included in the Profile study deal with health disparities, which highlight the end product of health inequalities. In order to attack the root cause of disparities and prevent them from happening in the first place, future studies may lay emphasis on institutional policies, norms, and social structures responsible for creating structures of inequitable access to social determinants of health. Thirdly, as with most of the secondary qualitative data, the self-reported information was not independently verified. Finally, the unit of sampling and observation for the Profile study is individual LHD, but the LHDs included in the study have a lot of flexibility regarding who completes the survey. In some LHD's Profile surveys the questionnaire is completed by LHD top leadership, while in other LHDs programmatic staff complete the survey, and yet multiple staff members from different functional units complete the survey in some others. This variation in level of staff may have resulted in variation in respondents' understanding of the term (health disparities) and their knowledge about specific strategies to deal with health disparities by the LHDs, resulting in some systematic bias. Additionally, different factors may influence different types of disparities and the way a LHD is able to address them, might be different as well. Lastly, the type of health disparity present varies by the community served. Many factors including population, socio-economic status, environment, etc. can affect the type of health disparity present in that community. This could influence the measurement of health disparities.

\section{Conclusions}

Health disparities, an outcome of socio-political and economic inequities, constitute a critical public health issue but some LHDs seem to have experienced a reduction in their capacity to address health disparities. A significant reduction in the proportion of LHDs performing certain activities that can potentially address health disparities implies that LHDs need to recover from recent resource shortages after the budget cuts and staff reductions associated with recent recession of 2007-2008. LHDs lacking the scale and scope required for engaging in activities targeting reduction in health disparities may consider cross-jurisdictional resource sharing as a strategy to build economies of scale. Increase in LHDs' ability to engage in activities to address health disparities associated with their informatics capacity is among many other potential benefits of the health information technology and information systems. Policies aimed at improving capacity of public health systems to address disparities should consider investments in building robust informatics capacity of LHDs. The benefits of completing CHA, CHIP and SP (the three pre-requisites of PHAB accreditation) are also highlighted by our research. Future research should collect primary data on the extent to which LHDs engage in tackling health disparities adequately by collecting qualitative data on institutional practices that create inequities.

Acknowledgments: The authors gratefully recognize insights shared by Richard Hofrichter, Senior Director for Health Equity, National Association of County \& City Health Officials (NACCHO) in a personal conversation that 
greatly helped in framing the discussion of our results. We sincerely appreciate Dr. Hofrichter's expert advice. We also extend our sincere thanks to NACCHO for providing the profile study data for this research.

Author Contributions: Gulzar Shah was responsible for conception of this research, acquisition and analysis of the data, and interpretation of results. John Sheahan and Shah carried out the review of the literature and jointly developed all other section of the manuscript. Both authors read and approved the final manuscript.

Conflicts of Interest: The authors declare no conflict of interest. The study is unfunded.

\section{References}

1. Braveman, P. What are health disparities and health equity? We need to be clear. Public Health Rep. 2014, 129, 5-8. [PubMed]

2. Bleich, S.; Jarlenski, M.; Bell, C.; Laveist, T. Health inequalities, trends, progress, and policy. Annu. Rev. Public Health 2012, 33, 7-40. [CrossRef] [PubMed]

3. Pais, J. Cumulative structural disadvantage and racial health disparities: The pathways of childhood socioeconomic influence. Demography 2014, 51, 1729-1753. [CrossRef] [PubMed]

4. Scannapieco, F.; Shay, K. Oral health disparities in older adults, oral bacteria, inflammation, and aspiration pneumonia. Dent. Clin. N. Am. 2014, 58, 771-782. [CrossRef] [PubMed]

5. Strutz, K.; Herring, A.; Halpern, C. Health disparities among young adult sexual minorities in the U.S. Am. J. Prev. Med. 2015, 48, 76-88. [CrossRef] [PubMed]

6. Persson, T.; Pfaus, J.; Ryder, A. Explaining mental health disparities for non-monosexual women, Abuse history and risky sex, or the burdens of non-disclosure? Soc. Sci. Med. 2015, 128, 366-373. [CrossRef] [PubMed]

7. Bridges, A.; Andrews, A.; Villalobos, B.; Pastrana, F.; Cavell, T.; Gomez, D. Does integrated behavioral health care reduce mental health disparities for Latinos? Initial findings. J. Lat. Psychol. 2014, 2, 37-53. [CrossRef] [PubMed]

8. Cadoret, C.; Garcia, R. Health disparities and the multicultural imperative. J. Evid.-Based Dent. Pract. 2014, 14, 160-170. [CrossRef] [PubMed]

9. Grembowski, D.; Bekemeier, B.; Conrad, D.; Kreuter, W. Are local health department expenditures related to racial disparities in mortality? Soc. Sci. Med. 2010, 71, 2057-2065. [CrossRef] [PubMed]

10. Asada, Y.; Yoshida, Y.; Whipp, A. Summarizing Social Disparities in Health. Milbank Q. 2013, 91, 5-36. [CrossRef] [PubMed]

11. Dubay, L.; Lebrun, L. Health, behavior, and health care disparities, disentangling the effects of income and race in the United States. Int. J. Health Serv. 2012, 42, 607-625. [CrossRef] [PubMed]

12. Jackson, C.; Gracia, J. Addressing health and health-care disparities, the role of a diverse workforce and the social determinants of health. Public Health Rep. 2014, 129, 57-61. [PubMed]

13. Islam, N.S.; Kwon, S.C.; Wyatt, L.C.; Ruddock, C.; Horowitz, C.R.; Devia, C.; Trinh-Shevrin, C. Disparities in diabetes management in Asian Americans in New York City compared with other racial/ethnic minority groups. Am. J. Public Health 2015, 105, 443-446. [CrossRef] [PubMed]

14. Bharel, M.; Santiago, E.R.; Forgione, S.N.; Leon, C.K.; Weinreb, L. Eliminating health disparities: Innovative methods to improve cervical cancer screening in a medically underserved population. Am. J. Public Health 2015, 105, 438-442. [CrossRef] [PubMed]

15. Dankwa-Mullan, I.; Maddox, Y.T. Embarking on a science vision for health disparities research. Am. J. Public Health 2015, 105, 369-371. [CrossRef] [PubMed]

16. Chen, J.; Bustamante, A.V.; Tom, S.E. Health care spending and utilization by race/ethnicity under the Affordable Care Act's dependent coverage expansion. Am. J. Public Health 2015, 105, 499-507. [CrossRef] [PubMed]

17. McCarthy, A.M.; Yang, J.; Armstrong, K. Increasing disparities in breast cancer mortality from 1979 to 2010 for US black women aged 20 to 49 years. Am. J. Public Health 2015, 105, 446-448. [CrossRef] [PubMed]

18. Northridge, M.E.; Yu, C.; Chakraborty, B.; Port Greenblatt, A.; Mark, J.; Golembeski, C.; Cheng, B.; Kunzel, C.; Metcalf, S.S.; Marshall, S.E.; et al. A community-based oral public health approach to promote health equity. Am. J. Public Health 2015, 105, 459-465. [CrossRef] [PubMed] 
19. Roberts, M.C.; Wheeler, S.B.; Reeder-Hayes, K. Racial/Ethnic and socioeconomic disparities in endocrine therapy adherence in breast cancer: A systematic review. Am. J. Public Health 2015, 105, 4-15. [CrossRef] [PubMed]

20. Srinivasan, S.; Moser, R.P.; Willis, G.; Riley, W.; Alexander, M.; Berrigan, D.; Kobrin, S. Small is essential: Importance of subpopulation research in cancer control. Am. J. Public Health 2015, 105, 371-373. [CrossRef] [PubMed]

21. Young, J.L.; Pollack, K.; Rutkow, L. Review of state legislative approaches to eliminating racial and ethnic health disparities, 2002-2011. Am. J. Public Health 2015, 105, 388-394. [CrossRef] [PubMed]

22. Hamman, M.K.; Kapinos, K.A. Mandated coverage of preventive care and reduction in disparities: Evidence from colorectal cancer screening. Am. J. Public Health 2015, 105, 508-516. [CrossRef] [PubMed]

23. Shah, G.; Laymon, B.; Leep, C.; Elligers, J. Community Health Assessment Activity by Lhds, the Influence of Local Health Agency and Community Characteristics: The Influence of Local Health Agency and Community Characteristics. In Proceedings of the Oral presentation at Academy Health Annual Research Meeting, Baltimore, MD, USA, 25 June, 2013.

24. Shah, G.; Laymon, B.; Elligers, J.; Leep, C.; Bhutta, C. Community Health Assessment by Local Health Departments. Presence of Epidemiologist, Governance, and Federal and State Funds are Critical. Front. Public Health Serv. Syst. Res. 2013, 2. Available online: http://uknowledge.uky.edu/ cgi/ viewcontent.cgi?article= 1063\&context=frontiersinphssr (accessed on 16 November 2015).

25. Institute of Medicine (US). How Far Have We Come in Reducing Health Disparities? In Progress since 2000: Workshop Summary; National Academies Press (US): Washington, DC, USA, 2012. Available online: http:/ / www.ncbi.nlm.nih.gov/books/NBK100492/ (accessed on 9 June 2015).

26. U.S. Centers for Disease Control and Prevention. Community Health Assessment for Population Health Improvement, Resource of Most Frequently Recommended Health Outcomes and Determinants. Available online: http://wwwn.cdc.gov/CommunityHealth/PDF/Final_CHAforPHI_508.pdf (accessed on 15 July 2015).

27. Public Health Accreditation Board. (1 December 2013). Available online: http://www.phaboard.org/ wp-content/uploads/SM-Version-1.5-Board-adopted-FINAL-01-24-2014.docx.pdf (accessed on 29 June 2015).

28. LaVeist, T.A.; Gaskin, D.; Richard, P. Estimating the economic burden of racial inequalities in the United States. Int. J. Health Serv. 2011, 41, 231-238. [CrossRef] [PubMed]

29. Shankardass, K.; Renahy, E.; Muntaner, C.; O'Campo, P. Strengthening the implementation of Health in All Policies: A methodology for realist explanatory case studies. Health Policy Plan. 2015, 30, 462-473. [CrossRef] [PubMed]

30. Luo, H.; Sotnikov, S.; Shah, G. Local health department activities to ensure access to care. Am. J. Prev. Med. 2013, 45, 720-727. [CrossRef] [PubMed]

31. Erwin, P.C.; Mays, G.P.; Riley, W.J. Resources that may matter, the impact of local health department expenditures on health status. Public Health Rep. 2012, 127, 89-95. [PubMed]

32. Bekemeier, B.; Grembowski, D.; Yang, Y.R.; Herting, J.R. Local Public Health Delivery of Maternal Child Health Services, Are Specific Activities Associated with Reductions in Black-White Mortality Disparities? Matern. Child Health J. 2012, 16, 615-623. [CrossRef] [PubMed]

33. Ye, J.; Leep, C.; Newman, S. Reductions of budgets, staffing, and programs among local health departments: Results from NACCHO's economic surveillance surveys, 2009-2013. J. Public Health Manag. Pract. 2015, 21, 126-133. [CrossRef] [PubMed]

34. Willard, R.; Shah, G.H.; Leep, C.; Ku, L. Impact of the 2008-2010 economic recession on local health departments. J. Public Health Manag. Pract. 2012, 18, 106-114. [CrossRef] [PubMed]

35. Novick, L.F. Local health departments: Time of challenge and change. J. Public Health Manag. Pract. 2012, 18, 103-105. [CrossRef] [PubMed]

36. Handler, A.S.; Turnock, B.J. Local health department effectiveness in addressing the core functions of public health: Essential ingredients. J. Public Health Policy 1996, 17, 460-483. [CrossRef] [PubMed]

37. Santerre, R.E. Jurisdiction size and local public health spending. Health Serv. Res. 2009, 44, $2148-2166$. [CrossRef] [PubMed] 
38. National Association of County \& City Health Officials. 2005 National Profile of Local Health Departments. Available online: http://www.naccho.org/topics/ infrastructure/profile/upload/ NACCHO_report_final_ 000.pdf (accessed on 7 May 2015).

39. National Association of County \& City Health Officials. 2008 National Profile of Local Health Departments. Available online: http://nacchoprofilestudy.org/wp-content/uploads/2014/01/NACCHO_2008_ ProfileReport_post-to-website-2.pdf (accessed on 7 May 2015).

40. National Association of County \& City Health Officials. 2010 National Profile of Local Health Departments. Available online: http:/ / nacchoprofilestudy.org/materials/2010-profile-study/ (accessed on 7 May 2015).

41. National Association of County \& City Health Officials. The 2013 National Profile of Local Health Departments. Available online: http:/ /nacchoprofilestudy.org (accessed on 22 June 2015).

42. Public Health Accreditation Board Standard and Measures (Version 1.5). Adopted December 2013. Available online: http://www.phaboard.org/wp-content/uploads/SM-Version-1.5-Board-adopted-FINAL-0124-2014.docx.pdf (accessed on 24 July 2015).

43. National Association of County and City Health Officials. Data Requests \& Technical Documentation, GIS Shapefiles (2008-13). Available online: http://nacchoprofilestudy.org/data-requests/ (accessed on 22 March 2015).

44. Krieger, N. Discrimination and health inequities. Int. J. Health Serv. 2014, 44, 643-710. [CrossRef] [PubMed]

45. Penman-Aguilar, A.; Harrison, K.M.; Dean, H.D. Identifying the root causes of health inequities: Reflections on the 2011 National Center for HIV/AIDS, Viral Hepatitis, STD, and TB Prevention health equity symposium. Public Health Rep. 2013, 128, 29-32. [PubMed]

46. Reschovsky, A.; Zahner, S.J. Forecasting the revenues of local public health departments in the shadows of the "Great Recession". J. Public Health Manag. Pract. 2013. [CrossRef] [PubMed]

47. National Association of County \& City Health Officials. Developing a Local Health Department Strategic Plan: A How-to Guide. Available online: http:/ /www.naccho.org/topics/infrastructure/ accreditation/ upload/strategicplanningguidefinal.pdf (accessed on 29 August 2015).

48. Erwin, P.C. The performance of local health departments: A review of the literature. J. Public Health Manag. Pract. 2008, 14, 9-18. [CrossRef] [PubMed]

(C) 2015 by the authors; licensee MDPI, Basel, Switzerland. This article is an open access article distributed under the terms and conditions of the Creative Commons by Attribution (CC-BY) license (http://creativecommons.org/licenses/by/4.0/). 